\title{
Patient Satisfaction: Receiving a copy of the GP letter following fracture or elective orthopaedic clinic
}

\author{
Elizabeth Pinder, S Jefferys, Mark Loeffler \\ Colchester General Hospital
}

\begin{abstract}
Following orthopaedic/fracture clinics at our hospital, patients now receive a copy of the letter summarizing an outpatient consultation that is sent to their General Practitioner. We undertook a patient satisfaction questionnaire to determine if patients found this change in practice beneficial.
\end{abstract}

Of the 83 patients who had received this letter, most patients had read the letter (96\%) and understood the content (90\%). 13\% were worried after having read the content and $86 \%$ found it helpful. Of the 40 patients who did not receive a copy, $32(80 \%)$ specified that they would wish to in the future. The results support the new practice although it could be improved by identifying those who do not wish to be included thereby reducing costs.

\section{Problem}

Until recently it has been common practice in our orthopaedic department that a letter summarizing an outpatient consultation is sent solely to the patients' GP. This was recently changed and patients are now included in correspondence. We undertook a patient satisfaction questionnaire to determine if patients found this change in practice to be beneficial. Anecdotal evidence showed that some secretaries have been contacted by patients either having not understood the letter or having concerns regarding the content. It is particularly important to assess the patient perceived value of this practice given the annual cost.

\section{Background}

There are a number of published studies across a variety of disciplines showing a positive patient response to receiving a copy of the GP letter. Otolaryngology patients understood the GP letter in $94 \%$ of cases. [1] Vascular, gastroenterology, dermatology and ophthalmology oncology patients also found the letter beneficial. [2-5]

Not all published studies demonstrate such a positive response. A UK study invited ENT patients to complete a survey following their outpatient consultation. [6] Only $43 \%$ wished to receive a copy of their GP letter and on receipt of this, $60 \%$ found the letter helpful.

For orthopaedic patients, a previous study found that interest in receiving a letter was also low, with $0.3 \%$ requesting a copy of their GP letter. [7] However, a limitation of this study was the potential introduction of responder bias since patients had to first register their interest by returning a completed form in a provided stamped addressed envelope.

Generating an additional copy of the GP letter is not without cost.
Not only does the practice double the paper, envelope and stamp cost, but it also requires additional secretarial time to fold and place them into envelopes. From the surgeons perspective, increased time may be spent signing letters. It is therefore important to determine whether the practice is beneficial to patients. Following the introduction of a new policy at our hospital to routinely send patients a copy of the GP letter, we were interested in obtaining robust information on patient satisfaction with this process.

\section{Baseline Measurement}

Prior to the introduction of our policy to copy the patient into their GP letter, it was unknown objectively whether patients were satisfied with not having receiving this letter previously. Secretaries did not report that patients had telephoned or written to request a copy, although patients may not have necessarily realised that this option had been available.

\section{Design}

A policy was introduced into our department whereby a copy of the GP letter is routinely sent to the patient, if over 18 years old, in order to optimize communication. It is important that the individual understands their diagnosis and treatment. During the consultation the patient has an opportunity to ask questions, but the information given may be misunderstood or forgotten. It may therefore be useful for patients to receive written information to provide an opportunity to consolidate or generate understanding or raise questions/concerns if the information is not as the patient recollects.

\section{Strategy}

In order to assess the success of this new policy, a six question survey was created by the authors. After establishing whether the individual had received a copy of the letter, it was important to 
ascertain whether it had also been read. It was decided that important areas to assess were patient comprehension of the letter, anxiety generated, whether the process had been helpful, and finally whether they would like to receive letters in the future.

The wording of the questions was assessed by the authors to ensure no ambiguity. The paper questionnaire was distributed to patients by the clinic receptionist and collected by clinic nurses when the patient entered the consultation room.

The following six questions were generated by the authors:

1. Did you receive a copy of the letter sent to your GP after your last appointment?

2. Did you read the letter?

3. Did you understand the letter?

4. Did anything in the letter worry you or cause you any anxiety?

5. Did you find it helpful to be sent a copy of the letter?

6. If you were given the choice, would you like a copy of the GP letter after this appointment?

\section{Results}

124 patients responded, of which $83(67 \%)$ had received a letter following their appointment. Of the 83 who did receive a letter, $60 \%$ had attended fracture clinic, 39\% elective and 1\% unknown. Of those that responded there was a near equal gender distribution; $56 \%$ male and an age range from 18 to 83 years; a fair representation of our outpatient demographics. The graph shows the outcome of the questions surveyed. Of the 40 patients who did not receive a copy of the letter, $32(80 \%)$ would wish to in the future.

See supplementary file: ds2031.jpg - "patient satisfaction"

\section{Lessons and Limitations}

The protocol for our study involved the clinic receptionist distributing questionnaires to patients when they were presented to be booked in. This method was chosen to provide patients ample time to complete the questionnaire prior to their appointment. Our experience was that receptionists sometimes became overwhelmed with work at busy clinic times and therefore not all patients were given an opportunity to complete the form. This was therefore a limitation of our study. An alternative would have been for them to receive the paperwork during or at the end of the consultation, but this was not considered practical because of time restraints and the assumption that patients would be keen to leave the clinic as soon as the appointment was over.

The surgeons need to be aware that the letters are being sent direct to patients and some may have to modify their tone and language.

It is reassuring that the majority of patients surveyed were pleased with the practice. It was also clear however, that a small proportion of patients did not understand the content of the letter or find it helpful, and some felt that they would prefer not to receive such correspondence. Given the cost of sending these letters, excluding these patients might be considered beneficial. In practical terms however, this may be more of a challenge. The clinician or clinic nurse would need to make a note of each patient's preference for a letter and then relay this information to the secretary, who would individually remove the letter from the printing run.

A concern is that nearly a third of patients did not recall receiving a letter. We suspect that this may not be truly representative of our practice. Firstly, some questionnaires were inadvertently handed to parents/guardians of patients under the age of 18 years. This patient group do not routinely receive a copy of the GP letter. We excluded patients where age was available, but unfortunately age was unknown for nearly a half of respondents. If some of these respondents were children, then the percentage of patients who should have but did not receive the letter would be lower. Secondly, we would expect some patients attending follow up to have previously been seen prior to the introduction of this new practice and therefore will distort this particular result. Thirdly, patient recall bias may well also mean that the number of patients not receiving a letter is actually lower that we report.

Comments were invited at the end of the survey. The majority were positive but for patients who found the content of the letter troubling, only one volunteered their reason for this. The source of concern was an inaccuracy which was then corrected following contact with the department. This example reinforces the advantage of receiving correspondence. A further project may be useful to identify all sources of anxiety in order to see if preventing them from arising in future might be possible. One patient volunteered that they found the letter useful as they found it reassuring that their GP had the details on file. It would be interesting to identify why other patients found the letter useful and to see if there is an impact on reducing the number of GP appointments. These points were out of the scope of this project.

\section{Conclusion}

Our results demonstrate that most patients are satisfied with our current correspondence practice. Other studies have found similar results for some other specialties. [1-5]

Unfortunately although patient satisfaction is high, the process does not necessarily improve recall. [8] Demand for a copy of the GP letter is also influenced by the number of outpatient visits. Lepping et al found decreasing demand with increasing numbers of appointments. [9]

Although most of these studies have shown that receiving the GP letter is welcomed greatly by patients, results should be interpreted with caution. Non-responders may be less likely to read the GP letter or find it useful, which would introduce responder bias. This may also be a limitation of our study.

Patient specific letters have been considered by some authors. Improved patient comprehension of this letter was found [10] as might be expected, but there are conflicting results on whether 


\section{BMJ Quality Improvement Reports}

there is any advantage over receiving a copy of the GP letter. [3,11] Dictating a separate patient letter increases the time spent per consultation and it may be argued that this is unnecessary given patient satisfaction with the current process.

A small number of patients in our study did not wish to receive correspondence in future. Excluding these patients from the process may be beneficial to the patient as well as financially (cost of stationery and postage), but is potentially at the expense of secretarial and clinical staff's time.

\section{References}

1. Pothier DD, Nakivell $P$, Hall CE. What do patients think about being copied into their GP letters? Ann R CollSurgEngl 2007 Oct;89(7):718-21.

2. Brodie T, Lewis DR. A survey of patients views on receiving vascular outpatient letters. Eur J VascEndovascSurg 2010;39(1):5-10.

3. Eaden JA, Ward B, Smith H, Mayberry JF. Are we telling patients enough? A pilot study to assess patient information needs in a gastroenterology outpatient department. Eur $\mathrm{J}$ GastroenterolHepatol 1998;10(1):63-7.

4. Tomkins CS, Braid JJ, Williams HC. Do dermatology outpatients value a $c$ opy of the letter sent to their general practitioner? In what way and at what cost? ClinExp Dermatology 2004;29(1):81-6.

5. Krishna Y, Damato BE. Patient attitudes to receiving copies of outpatient clinic letters from the ocular oncologist to the referring ophthalmologist and GP. Eye (Lond) 2005;19(11):1200-4.

6. Liapi A, Robb PJ, Akthar A. Copying clinic letters to patients: a survey of patient attitudes. J LaryngolOtol 2007;121(6):588-91.

7. Singh S, Budeda B, Housden P. Do patients want copies of their GP letters? - our experience with 7250 patients. Int J ClinPract 2007;61(8):1407-9.

8. O'Reilly M, Cahill MR, Perry IJ. Writing to patients: a randomised controlled trial. Clin Med 2006;6(2):178-82.

9. Lepping P, Paravastu SC, Turner J, Billings P, Minchom P. Copying GP letters to patients: A comprehensive study across four different departments in a district general hospital. Health Informatics J 2010;16(1):58-62.

10. .Roberts NJ, Partridge MR. How useful are post consultation letters to patients? BMC Med 2006;4:2.

11. Mahadavan L, Bird NJ, Chadwick M, Daniels IR. Prospective assessment of patient directed outpatient communication from a patient and general practitioner perspective. Postgrad Med J 2009;85(1006):395-8.

\section{Declaration of interests}

Nothing to declare.

\section{Acknowledgements}

We would like to acknowledge the orthopaedic/fracture clinic receptionists for distributing the questionnaire and the clinic staff for collecting the responses. 